\title{
BMJ Open Incentivised case finding for depression in patients with chronic heart disease and diabetes in primary care: an ethnographic study
}

\author{
Sarah L Alderson, Amy M Russell, Kate McLintock, Barbara Potrata, Allan House, \\ Robbie Foy
}

To cite: Alderson SL, Russell AM, McLintock K, et al. Incentivised case finding for depression in patients with chronic heart disease and diabetes in primary care:

an ethnographic study. BMJ Open 2014;4:e005146. doi:10.1136/bmjopen-2014005146

- Prepublication history for this paper is available online. To view these files please visit the journal online (http://dx.doi.org/10.1136/ bmjopen-2014-005146).

Received 27 February 2014 Revised 22 July 2014 Accepted 24 July 2014

CrossMark

Leeds Institute of Health Sciences, University of Leeds, Leeds, UK

Correspondence to Dr Sarah L Alderson; s.l.alderson@leeds.ac.uk

\section{ABSTRACT \\ Objective: To examine the process of case finding for depression in people with diabetes and coronary heart disease within the context of a pay-for-performance scheme.}

Design: Ethnographic study drawing on observations of practice routines and consultations, debriefing interviews with staff and patients and review of patient records.

Setting: General practices in Leeds, UK.

Participants: 12 purposively sampled practices with a total of 119 staff; 63 consultation observations and 57 patient interviews.

Main outcome measure: Audio recorded consultations and interviews with patients and healthcare professionals along with observation field notes were thematically analysed. We assessed outcomes of case finding from patient records.

Results: Case finding exacerbated the discordance between patient and professional agendas, the latter already dominated by the tightly structured and timelimited nature of chronic illness reviews. Professional beliefs and abilities affected how case finding was undertaken; there was uncertainty about how to ask the questions, particularly among nursing staff.

Professionals were often wary of opening an emotional 'can of worms'. Subsequently, patient responses potentially suggesting emotional problems could be prematurely shut down by professionals. Patients did not understand why they were asked questions about depression. This sometimes led to defensive or even defiant answers to case finding. Follow-up of patients highlighted inconsistent systems and lines of communication for dealing with positive results on case finding.

Conclusions: Case finding does not fit naturally within consultations; both professional and patient reactions somewhat subverted the process recommended by national guidance. Quality improvement strategies will need to take account of our results in two ways. First, despite their apparent simplicity, the case finding questions are not consultation-friendly and acceptable alternative ways to raise the issue of depression need to be supported. Second, case finding needs to operate within

\section{Strengths and limitations of this study}

- Multisite ethnography of broadly representative general practices

- Triangulation through use of multiple sources of data.

- Potential for clinician and patient behaviour to alter as a response to being observed.

- Short periods of observation in each practice limiting range of types of behaviour observed.

- Observations within one geographical area, thereby potentially limiting generalisability.

structured pathways which can be accommodated within available systems and resources.

\section{INTRODUCTION}

The detection and management of depression associated with chronic physical illness represents a major challenge for primary care. Depression is twice as common in those with chronic physical illness such as coronary heart disease (CHD) and diabetes compared with those without chronic physical illness. ${ }^{1-4}$ Such comorbidity can make depression hard to recognise, especially as symptoms of depression (such as fatigue) overlap with those of chronic physical illnesses. ${ }^{5}$ Comorbidity is also associated with poorer outcomes, including mortality. ${ }^{3} 67$ One response is case finding, defined as selective screening for depression in populations at high risk, such as those with chronic illness. This has been recommended by national guidance in the $\mathrm{UK}^{8}$ and elsewhere. ${ }^{9}{ }^{10}$ The Quality and Outcomes Framework (QOF), a pay-for-performance scheme in UK primary care, rewarded depression case finding using two standard screening questions from the Patient Health Questionnaire-2 (PHQ-2) in 
all patients with CHD or diabetes. ${ }^{11}$ The PHQ-2 asks, "In the past two weeks, have you been bothered by: little interest or pleasure in doing things; and feeling down, depressed or hopeless?" ${ }^{2}$ Routine data suggested high levels of case finding, with a national average of $86 \%$ of eligible patients screened in 2011-2012. ${ }^{13}$

However, there are problems with both the rationale underpinning this recommendation and the means undertaken to promote its implementation in the UK.

First, there is no evidence that case finding for depression by itself improves patient outcomes. ${ }^{14}$ For case finding to be effective, it is important that potential cases are further assessed, diagnosed and offered appropriate clinical management within a structured clinical pathway. ${ }^{15-17}$ There was no closely allied incentive in the QOF programme for subsequent patient care. Case finding should also be considered against other recommended criteria for screening tests, such as acceptability and having an agreed policy about whom to treat as patients. ${ }^{18} 19$

Second, evidence on the effects of financial incentives on primary care practice is, at best, mixed. ${ }^{20-22}$ There are concerns that such incentives undermine professionals' intrinsic motivation, patient-centredness and continuity of care and have led to a 'tick box' culture as health professionals work through checklists for chronic illness management. ${ }^{21}{ }^{23-25}$ Health professionals themselves have expressed dissatisfaction with incentivised depression management, particularly the use of incentivised depression severity measurements, although patients value their use within consultations. ${ }^{26-28}$

Our accompanying interrupted time series analysis found that incentivised case finding increased new depression-related diagnoses in people with diabetes and CHD and perpetuated rising trends in new prescriptions of antidepressants. ${ }^{29}$ Even though this incentivised case finding ceased in 2013 due to lack of evidence of patient benefit, there are continuing calls for 'something to be done' to detect and treat depression in highrisk groups. ${ }^{30-32}$ However, the professional and patient experiences of incentivised case finding, how it affected clinical care, and its fit with the routines of practice life are poorly understood. We investigated the process of incentivised case finding during scheduled and opportunistic reviews of patients with diabetes and CHD.

\section{METHODS}

\section{Design and setting}

Our ethnographic design combined direct observation with interviews and review of patient records. We wanted to build an in-depth understanding of how patient case finding was conducted within the context of everyday practice life and routine patient care. The study took place in general practices in Leeds, UK.

\section{Participants}

We invited all practices in Leeds to participate. We then sought a purposive sample of practices using a four-by-two sampling frame based on whether practice QOF achievement was above or below the Leeds median, further stratified by list size and deprivation profiles. Practices that consented to participate were booked for a week of observation, during which we aimed to observe at least three consultations.

Practices sent letters of invitation and information packs to patients scheduled for chronic disease reviews within the observation week. We also approached patients attending for routine consultations to enable observation of opportunistic case finding. Practice staff identified patients due to be asked the case-finding questions and asked if they would be interested in participating when they arrived at reception for their appointment. All patients and professionals subsequently observed gave informed consent.

\section{Data collection and analysis}

An ethnographer (AMR) used a funnelling approach to observe and describe the context of and behaviours within the practice, ${ }^{33}$ moving to detailed observation and audio recording of consultations. Observation considered both verbal and non-verbal features including: how case-finding questions are framed and asked; events leading up to questioning; patient verbal and non-verbal reactions and responses and overall style of the consultation. This style of observation allowed the researcher to layer the analysis of the consultations with contextual information providing a richer interpretation of the observation data. She held semistructured debriefing interviews with patients who had been observed. The interviews aimed to explore patient views on the process and experience of the consultation in further depth. Unstructured interviews took place with the healthcare professionals involved in depression case finding and notes were taken on all discussions regarding depression case finding. We reviewed patients' medical records 6 weeks after observation to check for any subsequent clinical events related to depression identification and management. Events included appointments where mood was discussed, telephone consultations, depression severity assessments, referrals to mental health teams or talking therapies and new prescriptions for depression medication.

The perceived relative importance and organisation of QOF-related case finding may vary throughout the year. To partly ameliorate this, we observed two practices towards the end of the financial year when practices are typically working hardest to achieve QOF targets.

Transcribed data (interviews, observation transcripts and observation notes) were managed using NVivo9 and coded for themes. Thematic analysis was undertaken by two researchers, independently coding for the themes and then comparing codes and themes. The analysis was further refined by using a constant comparison of themes, and looking for negative cases in order to examine for similarities and differences within and between the patients' perception and observations in 
different centres. Finally, to improve the reliability and validity of data, we triangulated findings from all three data sources.

\section{RESULTS}

Twelve practices participated and a total of 63 patient consultations were observed (range 2-13 per practice; table 1). Practice characteristics were relatively balanced, with five having QOF achievement above the median for Leeds, five above median population deprivation scores and six above the median list size. Patients were most commonly male, aged 51-79 years and white British (table 2). Most (73\%) participants had diabetes and 9 (14\%) had a previous diagnosis of depression. Nine of the observed case findings took place 'opportunistically' within routine general practitioner (GP) appointments. The rest occurred within dedicated chronic disease clinics, usually with nurses.

On the basis of the available guidance, observations and interviews, we constructed a basic normative model of the process by which case finding was expected to improve depression detection and treatment (figure 1). We then identified a number of ways in which professional and patient behaviours and beliefs and the working patterns of general practices subverted or affected the operation of this model. We found five barriers: discordance between patient and professional agendas; professional uncertainty around how to undertake the case finding itself; reluctance to open a 'can of worms'; patients being unaware of depression risk or case finding taking place and competing practice priorities and inconsistent lines of communication around the management of potential cases of depression.

\section{Discordance between patient and professional agendas}

Case findings often occurred within tightly structured and time-limited chronic illness reviews required to document QOF processes of care, and appeared to

Table 1 Observed practice characteristics

\begin{tabular}{llllc}
\hline Surgery & $\begin{array}{l}\text { QOF } \\
\text { score*}^{*}\end{array}$ & $\begin{array}{l}\text { List } \\
\text { size* }\end{array}$ & $\begin{array}{l}\text { Deprivation } \\
\text { score* }^{*}\end{array}$ & $\begin{array}{c}\text { Patients } \\
\text { recruited }\end{array}$ \\
\hline Practice A & Low & Low & Low & 3 \\
Practice B & Low & High & High & 13 \\
Practice C & Low & High & Low & 5 \\
Practice D & High & High & Low & 6 \\
Practice E & High & High & High & 6 \\
Practice F & High & Low & High & 5 \\
Practice G & Low & High & Low & 5 \\
Practice H & Low & Low & Low & 5 \\
Practice I & High & High & Low & 4 \\
Practice J & Low & Low & High & 5 \\
Practice K & Low & Low & High & 4 \\
Practice L & High & Low & Low & 2 \\
*Compared to the Primary Care Trust median. \\
QOF, Quality and Outcomes Framework.
\end{tabular}

Table 2 Patient demographics in observed consultations

\begin{tabular}{|c|c|c|}
\hline & $\begin{array}{l}\text { Number of } \\
\text { patients }\end{array}$ & $\begin{array}{l}\text { Percentage of } \\
\text { patients }\end{array}$ \\
\hline \multicolumn{3}{|l|}{ Gender } \\
\hline Female & 21 & 33 \\
\hline Male & 42 & 67 \\
\hline \multicolumn{3}{|l|}{ Age group } \\
\hline $18-30$ & 7 & 11 \\
\hline $31-50$ & 5 & 8 \\
\hline $51-64$ & 18 & 29 \\
\hline $65-79$ & 28 & 44 \\
\hline $80+$ & 5 & 8 \\
\hline \multicolumn{3}{|l|}{ Chronic illness } \\
\hline CHD & 13 & 21 \\
\hline DM & 46 & 73 \\
\hline $\mathrm{CHD}$ and $\mathrm{DM}$ & 4 & 6 \\
\hline \multicolumn{3}{|l|}{ Ethnicity } \\
\hline White British & 49 & 78 \\
\hline Mixed British & 1 & 2 \\
\hline White Irish & 2 & 3 \\
\hline Chinese & 1 & 2 \\
\hline Black Caribbean & 5 & 8 \\
\hline Pakistani & 3 & 5 \\
\hline British Asian & 1 & 2 \\
\hline Indian & 1 & 2 \\
\hline \multicolumn{3}{|c|}{ Previous diagnosis of depression } \\
\hline Yes & 9 & 14 \\
\hline No & 54 & 86 \\
\hline
\end{tabular}

exacerbate existing discordance. This led to professionals disregarding attempts by patients to steer the consultation around to their own perceived needs. Patients were often not focused on and often did not understand the purpose of the review process and used the consultation as an opportunity to raise other problems. To manage this, professionals often interrupted patients or returned the consultation to its purpose, discounting clues that the patient had worries related to the chronic disease being reviewed or other illnesses.

Patient: [talking about hypoglycaemic attacks which were a subject of significant anxiety for this patient (revealed in interview after appointment)] Only time that I went funny, I had a tooth out and I'd had, I couldn't have any breakfast, or I didn't have any breakfast, because I don't like to be poorly when I've had teeth out, because I used to be when I was younger, am I talking and disturbing...

[Fieldnote] Nurse is trying to measure blood pressure; patient looks agitated.

Nurse: Yes, I think you just probably need to just be quiet for a couple of minutes while I check it, because it's even higher now! We want it to go down! Just try and relax. OK. Observation 29

At this stage in the consultation the patient became distressed, apparently wishing to discuss further their worries about hypoglycaemia. The professional subsequently moved the conversation on to another QOF 


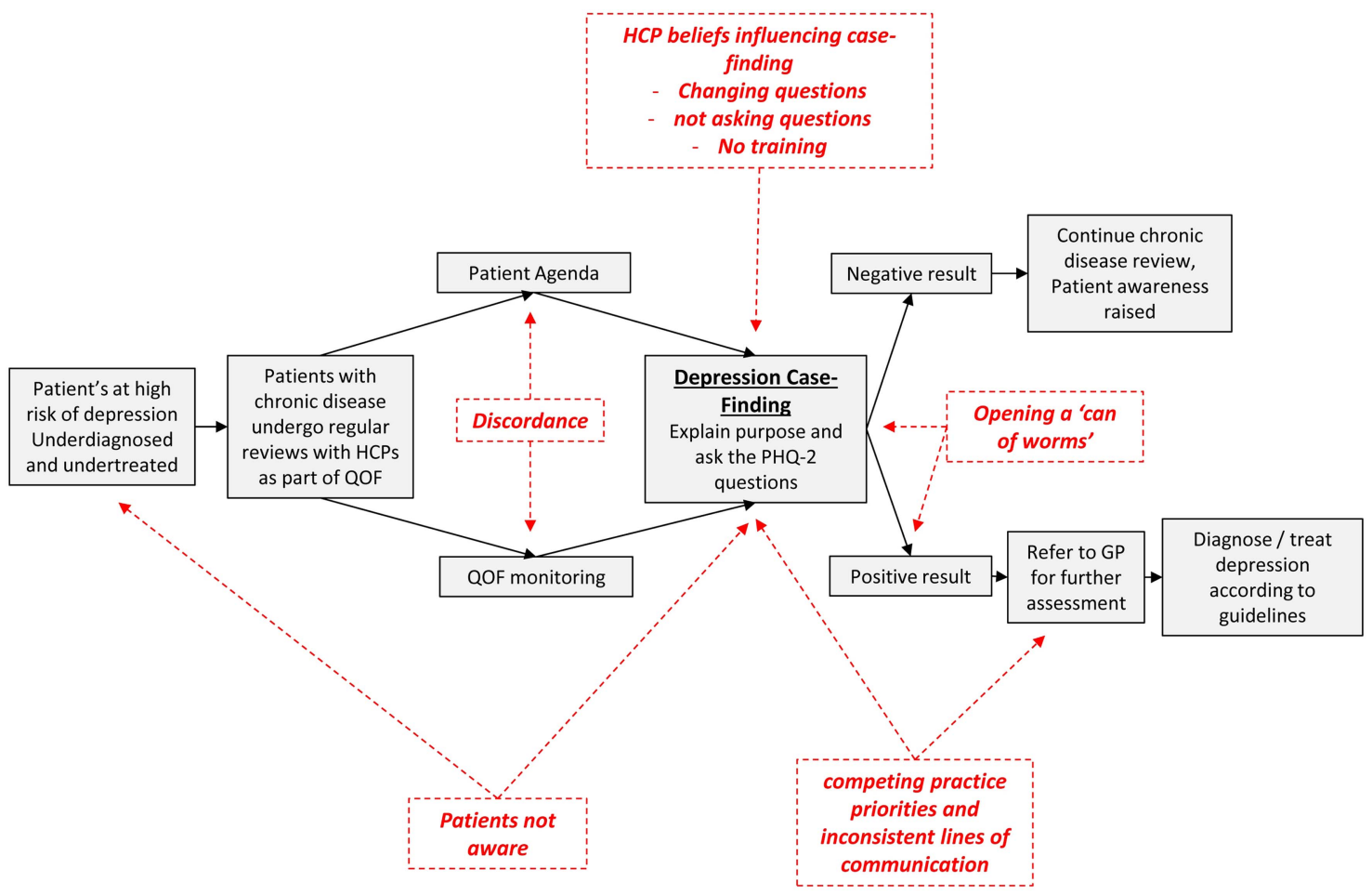

Figure 1 Flow chart of an idealised depression case-finding process and barriers identified.

target and no follow-up of concerns about hypoglycaemia was arranged. The patient later told the researcher that she was extremely worried about hypos and was experiencing a consistently low mood and high anxiety. The context of chronic illness reviews was restrictive-in this case, an opportunity for direct, subject-specific case finding was missed because of the necessity to ask about and record other items. This represents a missed opportunity for case finding at a point in the review when the patient might have been receptive to exploring associated mood problems.

Difficulties arose in the consultation when the patient mentioned a problem that the health professional perceived to be important but unrelated to the disease under review. Sometimes the review had to be abandoned as the patient's agenda became too important to be ignored, or the patient too distressed to continue concentrating on the review. This more patient-centred approach appeared to occur more often in practices that had a lower than average QOF achievement, suggesting that such practices traded off potential income against responsiveness to patients.

\section{Professional uncertainty around how to undertake the case finding itself}

Professional beliefs and abilities affected how case finding was undertaken. In conversation, professionals expressed uncertainty about how best to phrase and ask the questions, particularly nursing staff who told the researcher they sometimes felt insufficiently trained on how to manage patients with possible depression. When asked, they questioned whether they were case finding for QOF rather than patient benefit. We noticed that those who felt that the case finding was for the benefit of patients appeared to work in practices that were in areas of low deprivation, whereas those in areas of higher deprivation felt there was a lack of time to ask the questions and deal with any responses that might indicate a problem with mood. In the context of a timerestricted consultation, they felt overburdened.

Field notes Practice A: [The nurse] referred to QOF as coming from "on high" to tell her to incorporate it [casefinding]. She felt depression screening was problematic as they had received "no training" in mental health or in screening and they were very "stretched for time in the appointment."

Professionals avoided directly asking case-finding questions if they were familiar with patients but still recorded case finding; they expressed beliefs that they could identify mood changes through existing knowledge of patients. They often adapted the questions to suit their consultation style or perceived patient needs.

Sometimes confusion arose when the questions were framed to ask whether the patient was coping with their illness, rather than to assess mood disorders in general. The patient answered that they were managing their condition well but did not talk about their mood. This was because the professionals believed the case finding was to detect depression associated with chronic disease only, not depression of any cause. 
Nurse: Then so do you feel ok about your diabetes, do you have any, do you worry about it, does it bother you at all? Observation 27

The case-finding questions were usually asked in the middle of chronic disease reviews. Generally, the templates for such reviews were followed in order, with the depression case finding often occurring after discussion of alcohol consumption and smoking status. Once asked, the professional would move on to discuss diet and exercise. The case-finding questions appeared out of place in the consultation that mainly involved measuring physical factors rather than mood-related problems. When asked about the case finding, most nurses felt it was difficult to switch from asking something that could be measured (such as weight, units of alcohol consumed) to something more subjective.

\section{Reluctance to open a 'can of worms'}

Professionals at nearly every practice mentioned the term 'can of worms' to express unease with case finding for depression. This metaphor indicated professional perceptions of both patient discomfort with being asked about emotions and their own emotional labour in asking the questions. 'Can of worms' helped articulate the belief that case finding for depression was anticipated as a problematic part of the consultation and threatened to derail routines. Professionals anticipated having to manage and close down answers before patients began to give them; this often informed their immediate response to patients' answers regardless of what the patients said.

Many felt that by identifying a problem, it was their duty to uncover the scale of the problem and to discuss this further with the patient, rather than requesting that the patient should make an appointment to discuss this with the doctor or when there would be more time to devote to this. It was hard to move the consultation onto the rest of the review. This often led to the questions being asked in a manner that made it difficult for the patient to answer 'yes', such as "you have no problems coping, do you?" pre-empting any difficulties the questions may cause.

Then Nurse 1 said “it's a question that makes you sigh, makes your heart heavy, because you're there and you say "you've been down and depressed?" and she said "loads of them saying "yes" and she's thinking 'no, you're not, you're not, depressed, depressed, you're just a bit down, a bit fed up, aren't we all!' So then she has to say "Oh, why do you think that?" and it starts this 10 minute conversation that she really didn't want to be having, because she's had to do three blood pressure readings, loads of blood tests, trouble getting a vein, had to check their feet, loads of faffing around, she's only got 20 minutes. Field notes Practice F

Patients seldom answered with a simple 'yes' or 'no' and brought up specific difficulties, such as bereavement. Following an initial acknowledgement, professionals then tended to move consultations on without discussing the effects of these life events on mood. Therefore, professionals prematurely shut down patient responses suggesting emotional problems to reduce the risk of extended consultations.

Nurse: Are you alright, you haven't been having little interest in doing things, or?

Patient: No, no.

Nurse: Are you fine, are you okay? That's okay.

Patient: It's been 10 years since I've lost [woman's name].

Nurse: Is it, what, is that your wife?

Patient: Yes.

Nurse: 10 years? That's a long time, isn't it? Can I just check your tablets then, do you take aspirin, [lists medication]...Observation 23

Some healthcare professionals talked about the emotional labour involved in case finding. Discussing depression was seen as being emotionally difficult and required feeling strong in themselves, in order to cope with the answer. The emotional burden was exacerbated by the professional's perception that regardless of the outcome of case finding, there would not be any change for the better for the patient. They perceived they were expending a great deal of emotional labour on something that did not improve patient care and this compounded their feelings.

[The nurse] said she screened a woman with COPD who then cried and cried and then refused help and said she would sort herself out. This woman refused support and refused to quit smoking. Then she screened a man who was overweight and she'd just told him how serious his weight was and he cried about his weight and then she offered support with mood and weight loss and he said no. So she said most often it opens a can of worms, is demanding and difficult and rarely does anything come of it. Field notes practice B

\section{Patients being unaware of depression risk or case finding taking place}

Many patients undergoing case finding did not see themselves as the type of people who would be prone to depression and did not understand why they were being questioned. They appreciated the idea that people should experience case finding for depression but distanced themselves from the identity of those people. This sometimes led to defensive or even defiant answers, or deflecting questions with humour in an apparent attempt to illustrate how preposterous it was to suspect that they might be suffering from depression. This contradictory position of wanting everyone else to experience case finding, seeing the purpose/necessity of asking the questions but, in contrast, not feeling they should be questioned and thus derided the process or made light of it. This illustrates that the case-finding process in itself does not impact on the patient's self- 
perception of who may suffer from depression and thus does not enable them to answer the questions honestly and openly. They were concerned that they were being seen as someone who could not cope. This occurred especially when the patient felt they needed to be defensive over their lifestyle choices, such as diet, exercise, alcohol consumption, and just before being asked casefinding questions. The review was seen as a 'telling off' for not doing the right things, which then made it difficult to answer subjective questions about mood.

Nurse: So during the past month have you been bothered by feeling down or depressed or hopeless at all?

Patient looks perplexed.

Patient: I'm always... (His voice cracks and pretends to cry and rub his eyes like a child) Am I heck!

Fieldnote: Nurse shuffles in her seat and leans forward.

She's smiling but not $100 \%$ comfortable. Observation 24

Interviewed patients articulated the belief that the professionals would pick up mood problems or not coping without the need for such questions. They felt that being aware of depression was important in a generalised context but it did not fit with who they were, and so they found it hard to understand in the context of a chronic disease review.

Patient: I mean if you're, if you're down they don't have to ask, they know so they start talking about it. Interview 2

Several patients admitted difficulty with answering questions about mood within the chronic disease review during the interviews. They did not feel it was the appropriate place to discuss mood and that the chronic disease review took over the consultation. Some mentioned that they would like to be asked about mood at a separate appointment, although they also understood the difficulties in achieving this.

Just the fact that it's like a, a review appointment and that I'm under time pressure so it's not, I feel like if I am to be asked about like depression and something like that, there has to be a separate one (I: right) or like something depression, or like mood, sort of like mental illness or like anxiety or whatever, like related, an appointment related specifically to that or like a clinic specifically related to that. Interview 21

Patients were mostly unaware of the increased prevalence of depression in chronic illness, although they felt they understood why it might occur. They suggested that introducing the case-finding questions following an explanation that depression was more common in chronic illness might facilitate disclosure; this rarely happened in practice.

Researcher: So when the nurse asks you about your mood...just like I'm trying to imagine your perspective, why do you think that she's asking these questions usually when you get asked?
Patient: I don't know really, I didn't know whether it was because of my history [of depression] or...I didn't realise that people with heart problems and diabetes get depressed. I suppose if you're not well or you've got on going things with you, I suppose it can depress you. Interview 44

\section{Competing practice priorities}

Practices varied in how they prioritised and organised case finding for depression. Some practices devoted a lot of time and energy while others considered that some elements of QOF, such as the depression indicators, required too much effort for too little gain.

Field notes, Practice B: This leads to a debate over the decision between QOF payments and the work put in to achieve those payments. GPs are saying they should "choose their battles."

One practice did not concentrate on QOF at all and offered a different style of practice to their patients, with patients being seen as and when they wanted and most staff being unaware of the QOF domains and items needed, or where to find them on the computer system. Despite this, the nursing staff still used the QOF template to conduct the chronic disease reviews.

I ask how many patients haven't been screened for depression in the last 15 months. No one knows how to find this out (including the Practice Manager and the IT guy). Field notes Practice J

Five out of 63 patients had positive results to case finding; practices subsequently acted on one of these. Two patients who had negative case finding subsequently consulted to seek help for mood problems. Our follow-up highlighted inconsistent systems and lines of communication within practices for dealing with positive results on case finding. Although GPs were aware that nursing staff undertook case finding, many did not know how a positive case finding would be communicated to them. Nurses assumed that GPs reviewed the case-finding outcome when seeing patients following reviews, but this was seldom the case. For example, one patient who had a positive result was asked to return a PHQ-9 which indicated moderate depression symptoms. This was filed without notification to a GP and only picked up on our clinical record review.

Practices in areas with less deprivation seemed more likely to have a specified system for following up positive case-finding results.

[The nurse] said if they answered they were depressed she'd do the PHQ9 with them and make them an appointment to see the Dr but she felt the Dr wouldn't do anything for them and doing the PHQ9 makes her run late so she's conflicted about how useful it is to screen if you feel no one cares about the result. Field notes Practice A 
[The doctor] said she didn't really look at the mental health stuff. I said "Is there like a system in place or does a score of two trigger anything, or?" and she said "no, maybe we need to look at that." But she left it there. Field notes Practice F

\section{DISCUSSION}

Case finding for depression did not naturally fit within primary care consultations. It appeared to cause discordance between professionals and patients. Professionals struggled to align case finding with a person-centred approach and were wary of the risk of patients' emotional issues derailing routine reviews. Professionals believed it was good to ask about mental health but disliked the structure of the PHQ-2 and feeling forced to add it to consultations. They subsequently responded by going 'off script' or discounting cues. Patients sometimes did not understand why case-finding questions were being asked, or they did not see themselves as the type of people prone to depression. This led to defensiveness or even defiance in their responses, especially if not anticipated as part of their review. Practice responses to case-finding outcomes were haphazard, which may have reflected professional ambivalence towards depression case finding and the available treatment options for those identified as having depression.

Case finding for depression exemplifies what happens when attempts are made to fit apparently straightforward but deceptively complex interventions into primary care consultations and systems. Previously, anecdotal evidence and interviews with GPs have suggested that implementing case finding was more difficult than intended. $^{27} 3435$ This study provides clear evidence to the barriers faced by professionals and patients in implementing depression case finding in practice, as well as observational data of what actually happens in practice that both parties may not be aware of. Implementing depression case finding is different to other QOF targets as the topic itself is subject to significant stigma from both parties.

This study provides the strongest evidence yet that the principle of interrupting the flow of clinical conversation to ask out-of-context questions about sensitive issues has many significant barriers in clinical consultations. Much has been written about how QOF checklist approaches have disrupted consultation flows and led to the patient agenda being unheard. ${ }^{36-39}$ This is part of a wider phenomenon. For example, Rousseau et at demonstrated how a set of computerised prompts conflicted with established consultation processes. Adding the case-finding questions to these processes is inappropriate when the scripts and protocols have already created discordance between agendas. Such experience highlights the need for systematic development and evaluation of such interventions to ensure acceptability and feasibility before a wider roll-out. ${ }^{41}$ Despite their apparent simplicity, our study has shown that depression case-finding questions were not implemented consistently within consultations and practice routines.

Our findings also help explain the lack of benefit of case finding when it is implemented outside of collaborative care models. ${ }^{14}$ We identified mixed attitudes towards case finding among both professionals and patients, coupled with the absence of agreed pathways for patient follow-up and management. Collaborative care, with explicit monitoring and structured management of both physical and mental health problems, could help alleviate some of the barriers identified in this study.

The study's limitations were mainly related to the nature of our observations and sampled practices. We were aware of the intrusive nature of observation and the likelihood that people behaved differently when under observation. For example, professionals may have made more of an effort to ask the PHQ-2 questions sensitively, or ask them at all. When possible, observation began following a period of familiarisation to allow the healthcare professional to grow used to the researcher's presence. A week may also be insufficient to fully understand all practice processes and relationships; however, similar approaches have produced substantial insights into healthcare organisational behaviour elsewhere. ${ }^{42}$ Even allowing for these limitations, it is striking how often professionals did deviate from recommended practice. Professionals and patients are often used to the presence of a third party during consultations for training purposes, although some of the nurses observed did comment on feeling under pressure to demonstrate that they were following procedures correctly.

The generalisability of our findings may be limited given that this study took place within one geographical area. However, Leeds is typical of UK cities in terms of social deprivation indices, demographics, characteristics of primary care services and distribution of common diseases such as CHD and diabetes. ${ }^{43}$ Furthermore, we sampled a relatively diverse range of practices and found that practice characteristics, such as deprivation and QOF achievement, affected how case finding was approached. Opportunistic case findings were underrepresented in our sample of 63 consultations, but we did not find any systematic differences from chronic disease review case findings in our analysis.

We identified a range of problems with incentivised case finding for depression. Our accompanying interrupted time series analysis indicates that incentivised case finding did change clinical behaviour, increasing new depression-related diagnoses and, compared with untargeted patients with chronic illness, perpetuated increasing rates of antidepressant prescribing. ${ }^{29}$ It is difficult to predict with any confidence whether greater changes would have occurred if case finding had been applied with greater fidelity. However, our findings have broader implications for efforts to improve detection of depression in people with chronic illness.

Specifically, all of the patients, professionals and healthcare systems need to be prepared in advance of 
case finding. First, for patients, experience with the diagnostic disclosure of illnesses such as dementia and cancer suggests that acceptance is facilitated by a series of negotiated steps rather than a 'one-off' process. ${ }^{44} 45$ For example, patients in our study indicated that they would have been more receptive to case finding had they received information beforehand about the higher prevalence of depression in chronic physical illness. It is also possible that the act of case finding does form an initial step in helping patients consider and come to terms with a diagnosis of depression, given that we found patients with negative case finding subsequently consulted with mood problems. Second, professional attitudes towards and skills required in the detection of depression need to be examined. Some voiced unease about whether they were incorporating the questions correctly within consultations or uncertainty about how to handle potential new diagnoses, particularly nursing staff. Third, resources and care pathways need to be optimised to accommodate detection and follow-up. Patients identified through case finding are more likely to have mild-moderate rather than severe depression and less likely to benefit from antidepressant treatment. ${ }^{46} 47$ Resources are needed to manage those identified through case finding recommended by clinical guidelines. Health professionals were understandably reluctant to open up a 'can of worms' during tightly restricted chronic illness reviews; the exploration of sensitive issues requires greater flexibility in consultation time. We also found instances where positive results on case finding were not acted on given the absence of explicitly agreed pathways within practices.

There are more general lessons beyond depression detection. Mood disorders are not the only sensitive issue raised during chronic illness reviews. Our findings should prompt a reappraisal of how such reviews are designed and implemented for other emotionally laden problems integral to chronic illness care, such as weight management, sexual dysfunction and alcohol misuse. ${ }^{48}$ Health professionals may welcome structured protocols to help ensure coverage of key issues; there is evidence that prompting interventions have a small-to-modest effect on practice and patient outcomes. ${ }^{49}$ However, such approaches have been less successful in addressing relatively complex clinical behaviours, especially for chronic illness management. ${ }^{50}$ The subsequent challenge for quality improvement programmes and research is to further explore and evaluate how to develop interventions which can be embedded within primary care systems and consultations to improve population outcomes while preserving patient-centred care. The National Institute for Health and Care Excellence guidance on implementation recommends direct observation of practice as one way to identify potential barriers to changing practice, ${ }^{51}$ and although we have demonstrated the value of direct observation in evaluating new policy initiatives compared with (say) interview studies alone, it is not routinely undertaken when introducing new QOF indicators. ${ }^{11}$
Incentivised case finding exacerbated tensions between perceived patient-centredness and the timelimited routine of the consultation. Both professionals and patients reacted to the imposition of case finding by adapting, or even subverting, the process recommended by national guidance. Despite their apparent simplicity, the case-finding questions are not consultation-friendly, and acceptable alternative ways to raise mood disorders merit further exploration, as well as guidance on how to introduce the questions so patients do not feel depression is something that happens to 'other people' as our patient's awareness theme suggests. Practice teams need clearer guidance on the pathway for people with likely depression, which can be accommodated within available systems and resources.

Contributors $\mathrm{RF}$ and $\mathrm{AH}$ conceived the project. RF was the principal investigator. SLA and KM designed the study. SLA and AMR were responsible for running the project. AMR was responsible for data collection. All authors interpreted the data and findings. SLA wrote the first draft of the manuscript. RF commented on the first draft and all authors commented on further revisions. SLA is the guarantor of the paper.

Funding This paper summarises independent research funded by the National Institute for Health Research (NIHR) under its Research for Patient Benefit (RfPB) Programme (Grant Reference Number PB-PG-0110-21046). All authors had full access to all of the data in the study and can take responsibility for the integrity of the data and the accuracy of the data analysis.

Competing interests All authors received funding from National Institute of Health Research to undertake this study.

Ethics approval This study was approved by the South West-Exeter Research Ethics Committee (reference 11/SW/0335).

Provenance and peer review Not commissioned; externally peer reviewed.

Data sharing statement No additional data are available.

Open Access This is an Open Access article distributed in accordance with the Creative Commons Attribution Non Commercial (CC BY-NC 3.0) license, which permits others to distribute, remix, adapt, build upon this work noncommercially, and license their derivative works on different terms, provided the original work is properly cited and the use is non-commercial. See: http:// creativecommons.org/licenses/by-nc/3.0/

\section{REFERENCES}

1. Goldney RD, Phillips PJ, Fisher LJ, et al. Diabetes, depression, and quality of life. Diabetes Care 2004;27:1066-70.

2. Rudisch B, Nemeroff CB. Epidemiology of comorbid coronary artery disease and depression. Biol Psychiatry 2003;54:227-40.

3. Carney RM, Freedland KE, Miller GE, et al. Depression as a risk factor for cardiac mortality and morbidity: a review of potential mechanisms. J Psychosom Res 2002;53:897-902.

4. Anderson RJ, Freedland KE, Clouse RE, et al. The prevalence of comorbid depression in adults with diabetes: a meta-analysis. Diabetes Care 2001;24:1069-78.

5. Simon GE, VonKorff M. Recognition, management, and outcomes of depression in primary care. Arch Fam Med 1995;4:99-105.

6. Barth J, Schumacher M, Herrmann-Lingen C. Depression as a risk factor for mortality in patients with coronary heart disease: a meta-analysis. Psychosom Med 2004;66:802-13.

7. Katon W, Ciechanowski P. Impact of major depression on chronic medical illness. J Psychosom Res 2002;53:859-63.

8. National Institute of Clinical Excellence. Depression in adults with a chronic physical health problem: treatment and management. NICE, 2009.

9. New Zealand Guidelines Group. Identification of common mental disorders and management of depression in primary care. Wellington: An Evidence-based Best Practice Guideline, 2008. 
10. US Preventative Services Task Force. Screening for depression in adults: US preventive services task force recommendation statement. Ann Intern Med 2009;151:784-92.

11. University of Birmingham and University of York Health Economics Consortium. NM49 indicator development feedback report 2012.

12. BMJ Best Practice. Screening: Patient Health Questionnaire-2 (PHQ-2). BMJ Best Practice 2010. http://bestpractice.bmj.com/ best-practice/monograph/55/prevention.html

13. Health and Social Care Information Centre. Quality Outcomes Framework 2012/13 results. Secondary Quality Outcomes Framework 2012/13 results 2013. http://qof.hscic.gov.uk/index.asp

14. Gilbody S, Sheldon T, House A. Screening and case-finding instruments for depression: a meta-analysis. CMAJ 2008;178:997-1003.

15. Dowrick C, Buchan I. Twelve month outcome of depression in general practice: does detection or disclosure make a difference? BMJ 1995;311:1274-6.

16. Gilbody SM, House A, Sheldon T. Screening and case finding instruments for depression. Cochrane Database Syst Rev 2009;3:3.

17. Pignone MP, Gaynes BN, Rushton JL, et al. Screening for depression in adults: a summary of the evidence for the US Preventive Services Task Force. Ann Intern Med 2002;136:765-76.

18. Gilbody S, Sheldon T, Wessely S. Should we screen for depression? BMJ 2006;332:1027-30.

19. National Screening Committee. Programme Appraisal Criteria Secondary Programme Appraisal Criteria 2013. http://www screening.nhs.uk/criteria

20. Serumaga B, Ross-Degnan D, Avery A, et al. Effect of pay for performance on the management and outcomes of hypertension in the United Kingdom: interrupted time series study. BMJ 2011;342: d108.

21. Campbell SM, Reeves D, Kontopantelis E, et al. Effects of pay for performance on the quality of primary care in England. $N$ Engl $J$ Med 2009;361:368-78.

22. Scott A, Sivey $P$, Ait Ouakrim D, et al. The effect of financial incentives on the quality of health care provided by primary care physicians. Cochrane Database Syst Rev 2011;(9):CD008451.

23. Checkland K, Harrison S, McDonald R, et al. Biomedicine, holism and general medical practice: responses to the 2004 General Practitioner contract. Sociol Health IIIn 2008;30:788-803.

24. McDonald R, Harrison S, Checkland $\mathrm{K}$, et al. Impact of financial incentives on clinical autonomy and internal motivation in primary care: ethnographic study. BMJ 2007;334:1333-4.

25. Maisey S, Steel N, Marsh R, et al. Effects of payment for performance in primary care: qualitative interview study. $J$ Health Serv Res Policy 2008;13:133-9.

26. Mitchell C, Dwyer R, Hagan T, et al. Impact of the QOF and the NICE guideline in the diagnosis and management of depression: a qualitative study. Br J Gen Pract 2011;61:e279-89.

27. Coventry PA, Hays R, Dickens $C$, et al. Talking about depression: a qualitative study of barriers to managing depression in people with long term conditions in primary care. BMC Fam Pract 2011;12:10.

28. Dowrick C, Leydon GM, McBride A, et al. Patients' and doctors' views on depression severity questionnaires incentivised in UK quality and outcomes framework: qualitative study. BMJ 2009;338:6.

29. McLintock K, Russell AM, Alderson SL, et al. The effects of financia incentives for case finding for depression in patients with diabetes and coronary heart disease: interrupted time series analysis. BMJ Open 2014;4:e005178.

30. Practitioners RCoG. Supporting carers: an action guide for general practitioners and their teams. Royal College of General Pracitioners, 2011.
31. Burden AD, Boon MH, Leman J, et al. Diagnosis and management of psoriasis and psoriatic arthritis in adults: summary of SIGN guidance. BMJ 2010;341:c5623.

32. Collier F, Smith RC, Morton CA. Diagnosis and management of hidradenitis suppurativa. BMJ 2013;346:f2121.

33. Emerson RM, Fretz RI, Shaw LL. Writing ethnographic fieldnotes. 2nd edn. University of Chicago Press, 2011.

34. Anekwe L. QOF depression indicators face axe. Pulse 2011 (June 2011).

35. Maxwell M, Harris F, Hibberd C, et al. A qualitative study of primary care professionals' views of case finding for depression in patients with diabetes or coronary heart disease in the UK. BMC Fam Pract 2013;14:46.

36. Chew-Graham CA, Hunter C, Langer S, et al. How QOF is shaping primary care review consultations: a longitudinal qualitative study. BMC Fam Pract 2013;14:103.

37. Campbell SM, McDonald R, Lester $\mathrm{H}$. The experience of pay for performance in English family practice: a qualitative study. Ann Fam Med 2008;6:228-34.

38. Hannon KL, Lester HE, Campbell SM. Patients' views of pay for performance in primary care: a qualitative study. Br J Gen Pract 2012;62:e322-8.

39. Lester $\mathrm{H}$, Matharu T, Mohammed MA, et al. Implementation of pay for performance in primary care: a qualitative study 8 years after introduction. Br J Gen Pract 2013;63:e408-15.

40. Rousseau N, McColl E, Newton J, et al. Practice based, longitudinal, qualitative interview study of computerised evidence based guidelines in primary care. BMJ 2003;326:314.

41. Craig P, Dieppe P, Macintyre S, et al. Developing and evaluating complex interventions: the new Medical Research Council guidance. BMJ 2008;337:a1655.

42. Dixon-Woods M, Leslie M, Bion J, et al. What counts? An ethnographic study of infection data reported to a patient safety program. Milbank Q 2012;90:548-91.

43. Public Health England. National General Practice Profiles_Leeds PCT. Secondary National General Practice Profiles-Leeds PCT 2013. http://www.apho.org.uk/PracProf/Profile.aspx\#mod,2,pyr,2012, pat,2,par,E16000074,are,--sid1,2000002,ind1,243-4,sid2,2000005, ind2

44. Fallowfield L, Jenkins V. Effective communication skills are the key to good cancer care. Eur J Cancer 1999;35:1592-7.

45. Lecouturier J, Bamford C, Hughes J, et al. Appropriate disclosure of a diagnosis of dementia: identifying the key behaviours of 'best practice'. BMC Health Serv Res 2008;8:1-10.

46. Coyne JC, Schwenk TL, Fechner-Bates S. Nondetection of depression by primary care physicians reconsidered. Gen Hosp Psychiatry 1995;17:3-12.

47. Arroll B, Goodyear-Smith F, Crengle $S$, et al. Validation of $P H Q-2$ and $\mathrm{PHQ}-9$ to screen for major depression in the primary care population. Ann Fam Med 2010;8:348-53.

48. Crosson JC, Heisler M, Subramanian U, et al. Physicians perceptions of barriers to cardiovascular disease risk factor control among patients with diabetes: results from the Translating Research into Action for Diabetes (TRIAD) study. J Am Board Fam Med 2010;23:171-8.

49. Shojania KG, Jennings A, Mayhew A, et al. The effects of on-screen, point of care computer reminders on processes and outcomes of care. Cochrane Database Syst Rev 2009;(3):CD001096.

50. Grimshaw JM, Eccles MP, Lavis JN, et al. Knowledge translation of research findings. Implement Sci 2012;7:1-29.

51. National Institute for Health and Care Excellence. Into practice guide: using NICE guidance and quality standards to improve practice. https://www.nice.org.uk/About/What-we-do/Into-practice/ Into-practice-guide (accessed Aug 2014). 